\title{
PENGARUH KEPEMIMPINAN TRANSFORMASIONAL DAN EFIKASI DIRI TERHADAP ORGANIZATIONAL CITIZENSHIP BEHAVIOR GURU SMK NEGERI DI KABUPATEN BEKASI.
}

\author{
Herry Nugroho*
}

\begin{abstract}
: the objective of this research is to obtain information concerning to the effect of transformational leadership and self efficacy toward teachers organizational citizenship behavior in state vocational school in Bekasi district.The research was conduct by using survey method with path analysis in testing hyphotesis. In this research, 165 from 280teacher of teachers selected random sampling. The research was focused on three aspect; transformational leadership and self efficacy toward teachers OCB.The data were collected with questionnaire and analyzed with path analysis. Result on the analysis it is conculaded that (1) there the positive direct effect of transformational leadership toward $O C B$, (2) there is positive direct effect of self efficacy toward $O C B$ and (3) there is positive direct effect of transformational leadership toward self efficacy.
\end{abstract}

Keywords: OCB, transformational leadership, self efficacy

\section{PENDAHULUAN}

Sekolah merupakan sebuah organisasi yang seyogyanya dikelola sedemikian rupa agar seluruh aktifitas pelaksanaan program pendidikan dapat berjalan secara efektif dan efisien guna mencapai tujuan yang telah ditetapkan.Keberhasilan tujuan pendidikan di sekolah bergantung pada sumber daya manusia yang ada di sekolah, salah satunya guru.Sebagai sumber daya manusia yang memiliki peran penting di sekolah, para guru diharapkan dapat terus mengembangkan kompetensinya sesuai dengan perkembangan zaman.

Salah satu bentuk perkembangan yang terjadi adalah pergeseran pekerjaan yang tadinya dikerjakan secara individu menjadi bekerja secara tim. Dinamika ini pada akhirnya memunculkan pandangan baru yang dikaji dalam mencapai keberhasilan di suatu organisasi, dimana karyawan tidak hanya harus melakukan pekerjaan sesuai dengan tuntutan tugas ataupun sesuai dengan deskripsi pekerjaan, namun pekerja sangat disarankan untuk melakukan pekerjaan extra diluar dari tuntutan tugasnya yang disebut juga sebagai organizational citizenship behavior (OCB).

OCB merupakan perilaku positif orang-orang yang ada dalam organisasi,yang terekspresikan dalam bentuk kesediaan secara sadar dan sukarela untuk bekerja.Tingkat $O C B$ di Kabupaten Bekasi dapat dikatakan cukup rendah, hal ini terungkap pada saatpeneliti melakukan wawancara dengan tiga orang kepala sekolah pada tiga SMK Negeri di Kabupaten Bekasi. Indikator rendahnya OCB

*Guru PNS di SMKN 2 Cikarang Barat, Bekasi 
sering terlihat dari kurangnya rasa saling membantu di antara sesama guru dalam menggantikan guru yang tidak masuk sekolah, kurangnya koordinasi antar sesama guru sehingga cenderung mengambil keputusan sendiri dalam tim, guru sering mengeluh ketika dihadapkan pada situasi yang kurang menguntungkan, para guru sering terlambat pada jam masuk kelas, dan selain itu juga para guru bersedia menghadiri kegiatan tidak wajib bila hanya ada perintah dari kepala sekolah.

Permasalahan di atas diyakini disebabkan oleh berbagai faktor, salah satunya keyakinan diri seseorang untuk melakukan pekerjaan dengan baik (self efficacy). Self efficacy yang tinggi akan menunjukkan pribadi yang yakin akan kompetensi dan kemampuannya dalam melakukan pekerjaan. Keyakinan pada kemampuan diri sendiri inilah yang akan menimbulkan kepercayaan diri yang dapat digunakan untuk membantu para guru lain maupun bekerja melebihi beban kerja yang diberikan. Namun faktanya, dari pernyataan kepala sekolah di atas, self efficacy guru SMK Negeri di Kabupaten Bekasi dapat dikatakan masih rendah.

Selain itu faktor lain yang turut mempengaruhi OCB guru adalah kepemimpinan kepala sekolah. Dalam organisasi sekolah, guna memaksimalkan perilaku OCBguru diperlukan keefektifan peran pemimpin yang bersangkutan. Namun faktanya, permasalahan mengenai kepemimpinan kepala sekolah masih ditemukan di kabupaten Bekasi. Permasalahan kepemimpinan yang ditemukan berdasarkan wawancara sementara dengan tujuh orang guru secara acak pada limaSMK Negeri di Kabupaten Bekasi menyatakan bahwa kurangnya motivasi dan interaksi yang diberikan pihak kepala sekolah kepada guru sehingga mempengaruhi kurang optimalnya tugas yang dilakukan oleh guru.

Selain itu, model kepemimpinan kepala sekolah juga menjadi faktor yang mempengaruhi $O C B$ guru di sekolah. Menurut Zain Masrifah (2013, salah satu model kepemimpinan pendidikan yang diprediksi mampu mendorong terciptanya efektifitas institusi pendidikan adalah kepemimpinan transformasional. Jenis kepemimpinan ini menggambarkan adanya tingkat kemampuan pemimpin untuk mengubah mentalitas dan perilaku pengikut menjadi lebih baik dengan cara menunjukkan dan mendorong mereka untuk melakukan sesuatu yang kelihatan mustahil. Konsep kepemimpinan ini menawarkan perspektif perubahan pada keseluruhan institusi pendidikan, sehingga pengikut menyadari eksistensinya untuk membangun institusi yang siap menyongsong perubahan. Namun kenyataannya dari observasi yang peneliti lakukan, penerapan model kepemimpinan transformasional yang optimal di SMK Negeri Kabupaten Bekasi masih jauh dari harapan.

Penelitian ini menguji pengaruh langsung kepemimpinan transformasional terhadap $O C B$, pengaruh langsung efikasi diri terhadap $O C B$ dan pengaruh langsung kepemimpinan transformasional terhadap efikasi diri, dengan subjek penelitian adalah guru Sekolah Menengah Kejuruan (SMK) Negeri di Kabupaten Bekasi.

Menurut Colquittet.al., (2009:43), "citizenship behavior is defined as voluntary employee activities that may or may not be rewarded but that contribute to the organization 
by improving the overall quality of the setting in which work takes place". Didefinisikan bahwa, OCB merupakan kegiatan karyawan sukarela yang mungkin atau mungkin tidak dihargai, tetapi yang berkontribusi terhadap organisasi dengan meningkatkan kualitas keseluruhan pengaturan di mana pekerjaan berlangsung.

Sementara itu Jennifer M. George dan Gareth R. Jones (2012:87) mendefinisikan $O C B$ sebagai berikut, "organizational citizenship behavior (OCB) is behavior above and beyond the call of duty that is, behavior not required of organizational members but nonetheless necessary for organizational survival and effectiveness". Dikatakan bahwa $O C B$ sebagai perilaku yang melampaui panggilan tugas yaitu, perilaku yang secara tidak langsung diperlukan oleh anggota tapi tetap diperlukan untuk kelangsungan hidup dan efektivitas organisasi. Artinya anggota diasumsikan telah memenuhi kewajiban yang telah diamanatkan kepadanya namun ia menuntut dirinya melebihi atas tuntutan yang telah diamanatkan.

John R. Schermerhorn (2011:74) berpendapat, "organizational citizenship behaviors are the extras people do to go the extra mile in their work". Perilaku warga organisasi adalah orang-orang ekstra yang melakukan pekerjaan ekstra dalam pekerjaan mereka. Diartikan bahwa perilaku OCB hanya dimiliki oleh orang-orang yang minoritas artinya dalam suatu sekumpulan orang hanya sebagian kecil yang memiliki perilaku $O C B$ karena $O C B$ merupakan perilaku yang menuntut kesadaran bagi dirinya sendiri khususnya dalam meningkatkan kualitas dalam berbagai hal seperti kedisiplinan, integritas, komitmen dan lain-lain.

Steven L. McShane dan Mary Ann Von Glinow (2010:17) berpendapat bahwa, "organizational citizenship behaviors (OCBs) - various forms of cooperation and helpfulness to others that support the organization's social and psychological context". OCB adalah perilaku warga organisasi bentuk berbagai kerjasama dan menolong orang lain yang mendukung konteks sosial dan psikologis organisasi. Robbins dan Coulter (2012:373) menjelaskan, "organizational citizenship behavior is discretionary behavior that's not part of an employee's formal job requirements, but which promotes the effective functioning of the organization". Perilaku kewargaan organisasi (OCB) merupakan perilaku diskresioner yang bukan bagian dari persyaratan kerja formal karyawan, tetapi sebagai promosi fungsi efektif organisasi.

Menurut Morse, Buss dan Kinghorn (2007:109), "transformational leadership is leadership through formations of organizations and followers within them. Transforming leadership is thorugh the forming of self and others". Kepemimpinan transformasional adalah pemimpin yang pembentukannya melalui organisasi dan dimulai dari bawahan. Kepemimpinan transformasional pembetukannya melalui dirinya dan kehendak dari pihak lain.Hawkins (2011:10) mengungkapkan, "transformational leadership is the process of collectively engaging the commitment and participation of all major stakeholder groups to radical change in the context of shared endeavour, values and vision". Kepemimpinan transformasional adalah proses kolektif yang melibatkan komitmen dan partisipasi dari semua kelompok pemangku kepentingan untuk perubahan yang radikal dalam konteks usaha bersama, nilai-nilai dan visi. 
Sementara Schermerhorn (2012:272) mendefinisikan kepemimpinan transformasional sebagai, "transformational leadership is inspirational and arouses extraordinary effort and performance". Didefinisikan bahwa kepemimpinan transformasional adalah kepemimpinan yang mampu memberikan inspirasi yang lebih terhadap usaha dan kinerja.

Gibson et. al., (2006:355) berpendapat bahwa kepemimpinan transformasional, "ability to inspire and motivate followers to achive result greater than originally planned and for internal rewards".Pemimpin transformasional adalah pemimpin yang menginspirasi para pengikutnya untuk mengesampingkan kepentingan pribadi mereka demi kebaikan organisasi.

Senada dengan itu Robbins dan Judge (2011:312) mengungkapkan bahwa, "leader who able to stimulates and inspires or transform his or her subordinates to strive hard in order to achieve extraordinary". Dikatakan bahwa kepemimpinan transformasional adalah pemimpin yang mampu memberikan rangsangan atau stimulasi dan inspirasi yang dapat mentransformasikan bawahannya untuk bekerja lebih keras dalam mencapai hasil yang luar biasa.

Robbins dan Judge (2011:251) mengemukakan tentang efikasi diri yaitu, "selfefficacy (also known as social cognitive theory or social learning theory) refers to an individual's belief that he or she capable of performing a task". Dikatakan bahwa, efikasi diri (yang juga dikenal sebagai teori kognitif atau teori pembelajaran sosial) merujuk pada keyakinan individual bahwa dirinya mampu mengerjakan suatu tugas.

Sementara itu Slocum dan Hellriegel (2009:118) menyatakan, "self-efficacy refers to the individual estimate of his or her own ability to perform a spesific task in a particular situation". Efikasi diri adalah perkiraan individu tentang kemampuannya untuk melaksanakan suatu spesifikasi tugas dalam situasi tertentu.

Senada dengan itu, Bandura dalam Schermerhorn (2011:372) menyatakan, "self-efficacy is aperson's belief that she or he is capable of performing a task". Efikasi diri merupakan keyakinan seseorang bahwa dia mampu melakukan tugas tertentu. Hal ini menafsirkan anggapan bahwa semakin tinggi rasa efikasi diri seseorang, maka ia semakin mampu melaksanakan kemampuannya.Selanjutnya, Santrock (2008:462) berpendapat, "self-efficacy is the belief that one can master a situation and produce positive outcome". Efikasi diri merupakan keyakinan bahwa seseorang dapat menguasai situasi dan menghasilkan hasil yang positif.

Kinicki dan Fugate (2012:125) mengemukakan bahwa, "self-efficacy is a person's belief about his or her chances of successfully accomplishing a spesific task". Diartikan secara bebas, efikasi diri adalah keyakinan seseorang terhadap peluang yang dimilikinya untuk berhasil dalam menyelesaikan suatu tugas tertentu.

Robert Kreitner dan Angelo Kinicki (2010:114) juga menyatakan bahwa, "selfefficacy is a person belief about his or her chances of successfully accomplishing a specific task, "self-efficacy is belief in one's ability to do task". Efikasi dirimerupakan keyakinan diri seseorang untuk berkembang dan berhasil dalam tugas khusus, serta percaya untuk dapat melakukan pekerjaan. 


\section{METODE}

Metode peneltian yang digunakan pada penelitian ini adalah metode survey, dengan pendekatan kuantitatif. Penelitian ini dilakukan di SMK Negeri di Kabupaten Bekasi dan penelitian ini sebanyak 280 orang dengan sampel sebanyak 165 orang. Pengambilan sampel menggunakan teknik simple random sampling.

Penelitian ini menggunakan analisis jalur (path analysis) untuk mengetahui adanya pengaruh antar variabel sesuai dengan model kausal yang terbentuk.Sebelum kuesioner digunakan dalam penelitian ini, terlebih dahulu dilakukan ujicoba untuk menentukan validitas dan reliabilitas instrumen.Hasil tersebut digunakan sebagai instrumen untuk mengambil data penelitian di lapangan. Analisis data meliputi: 1) deskripsi data, 2) uji prasyarat analisis normalitas, 3) analisis jalur yang meliputi: analisis model, pengujian hipotesis dan penentuan tingkat pengaruh.

\section{HASIL DAN PEMBAHASAN}

Pengaruh Kepemimpinan Transformasional terhadap $O C B$

Dari hasil pengujian hipotesis pertama dapat disimpulkan bahwa terdapat pengaruh langsung positif kepemimpinan transformasional terhadap $O C B$ dengan nilai koefisien korelasi sebesar 0,223 dan nilai koefisien jalur sebesar 0,318.Ini memberikan makna kepemimpinan transformasional berpengaruh langsung terhadap $O C B$.

Hasil penelitian ini senada dengan pendapat beberapa ahli di antaranya adalahChamariyah, Achmad Sudiro, Noermijati dan Rofiaty (2015) dengan judul "The Effect of Transformational Leadership to Organizational Citizenship Behavior (OCB) and Employees Performance (Study Case to PT PLN Persero Pamekasan Area)". Peneliti menemukan bahwa analisis pada hipotesis kedua dimana kepemimpinan transformasional berpengaruh positif dan signifikan terhadap $O C B$ dapat diterima. Hal ini berarti meningkatnya $O C B$ karyawan dipengaruhi oleh gaya kepemimpinan transformasional.

$O C B$ guru mengacu pada perilaku positif yang memberikan keuntungan terhadap organisasi sekolah dan langsung mengarah pada peran guru secara signifikan. $O C B$ merupakan kontribusi guru yang mendalam melebihi tuntutan peran di sekolah. Jennifer M. George dan Gareth R. Jones (2012:87) mendefinisikan $O C B$ sebagai berikut, "organizational citizenship behavior (OCB) is behavior above and beyond the call of duty that is, behavior not required of organizational members but nonetheless necessary for organizational survival and effectiveness".

Diartikan secara bebas bahwaOCB sebagai perilaku yang melampaui panggilan tugas yaitu, perilaku yang secara tidak langsung diperlukan oleh guru tapi tetap diperlukan untuk kelangsungan hidup dan efektivitas organisasi sekolah. Artinya guru diasumsikan telah memenuhi kewajiban yang telah diamanatkan kepadanya namun ia menuntut dirinya melebihi atas tuntutan yang telah diamanatkan. 
OCB merupakan perilaku atau tindakan sukarela guru dalam mengerjakan sesuatu yang melebihi atau di luar dari tugas dan kewajibannya di sekolah. Tentu hal ini sangat diharapkan sekolah, karena semakin tinggi OCB guru, maka penyelenggaraan kegiatan di sekolah akan semakin lancar. Tentu hal ini tidak terlepas dari peran kepala sekolah, salah satunya dengan penerapan gaya kepemimpinan transformasional.

Menurut Gibson et. al., (2006:355) berpendapat bahwa kepemimpinan transformasional, "ability to inspire and motivate followers to achive result greater than originally planned and for internal rewards". Pemimpin transformasional adalah pemimpin yang menginspirasi para pengikutnya untuk mengesampingkan kepentingan pribadi mereka demi kebaikan organisasi.

Kepala sekolah yang menerapkan kepemimpinan transformasional adalah kepala sekolah yang mampu menjadi contoh dan memberi teladan kepada guru sehingga guru dapat termotivasi dan melakukan pekerjaan melebihi dari yang telah diamanatkan kepada guru. Dengan mampu menjadi teladan dalam bekerja keras demi organisasi, kepala sekolah secara langsung dapat meningkatkan perilaku sukarela $(O C B)$ guru terhadap setiap pekerjaan di sekolah.

Kepala sekolah yang menerapkan kepemimpinan transformasional mampu menstimulasi guru untuk bisa bekerja melebihi dari tugas wajib yang telah diberikan sekolah. Selain itu kepala sekolah juga mampu menjadi inspirasi guru untuk memiliki sikap kerja yang menolong rekan kerja tanpa pamrih, mampu menjaga hubungan baik dengan rekan guru lainnya, mampu menerapkan sikap sportif dengan mengakui kelebihan guru lain, dan sukarela untuk berpartisipasi dalam kegiatan organisasi.

Berdasarkan uraian di atas secara teoretik maupun empiris, kepemimpinan transformasional berpengaruh langsung positif terhadap $O C B$.

\section{Pengaruh Efikasi Diri terhadap OCB}

Dari hasil pengujian hipotesis kedua dapat disimpukan bahwa terdapat pengaruh langsung positif efikasi diri terhadap OCBdengan nilai koefisien korelasi sebesar 0,328 dan nilai koefisien jalur sebesar 0,239.Ini memberikan makna efikasi diri berpengaruh langsung terhadap $O C B$.

Hasil penelitian ini senada dengan pendapat beberapa ahli di antaranya adalahIram Naveed Sheikh (2015) dengan judul "The Impact Of Perfectionism and SelfEfficacy on Organizational Citizenship Behavior $(O C B)$ ".Penelitian menunjukkan korelasi positif antara $O C B$ dan Efikasi Diri.Peneliti mengartikan bahwa terdapat pengaruh antara efikasi diri dan $O C B$.

Steven L. McShane dan Mary Ann Von Glinow (2010:17) berpendapat bahwa, "organizational citizenship behaviors (OCBs) - various forms of cooperation and helpfulness to others that support the organization's social and psychological context". Diartikan bebas, $O C B$ adalah perilaku warga organisasi sekolah yang berbentuk dengan adanya berbagai kerjasama dan menolong orang lain yang mendukung konteks sosial dan psikologis organisasi sekolah. Dalam hal ini OCBguru lebih mengarah pada 
panggilan sosial dimana keinginan untuk membantu rekan kerja di sekolahsehingga tercipta suasana yang saling membantu, menghargai, dan toleransi antara sesama pekerja.

Selain mengajar, tentu seorang guru memiliki berbagai pekerjaan lain yang dihadapkan pada berbagai tantan gan dalam menyelesaikannya seperti membuat perangkat pembelajaran, menghadapi supervisi, menyelenggarakan kegiatankegiatan sekolah maupun menghadapi peserta didik di kelas maupun di luar kelas. Oleh karena itu, hubungan kerjasama dengan rekan guru lain tidak dapat terelakkan.

$O C B$ guru lahir dari perasaan sosial guru yang pada akhirnya melahirkan perilaku (tindakan) sosial terhadap rekan kerja di sekolah. Dari berbagai literatur disebutkan bahwa OCB sangat menguntungkan organisasi. Oleh karena itu semakin tinggi $O C B$ guru, semakin baik bagi organisasi sekolah. Hal inilah yang membuat kepala sekolah senantiasa memberikan motivasi dan dukungan agar guru semakin yakin akan dirinya dan tidak terbeban pada pekerjaaan.

Efikasi diri guru merupakan representasi dari keyakinan diri guru terhadap kemampuannya dalam menyelesaikan tugas dan pekerjaan dengan sukses. Santrock (2008:462) berpendapat, "self-efficacy is the belief that one can master a situation and produce positive outcome". Diartikan secara bebas, efikasi diri guru merupakan keyakinan guru bahwa dirinya dapat menguasai situasi dan menghasilkan hasil yang positif. Keyakinan diri yang tinggi tentu akan membuat guru siap menghadapi segala kondisi yang ada di sekolah.

Kesiapan guru dalam menghadapi berbagai pekerjaan di sekolah tentu akan melahirkan perasaan sukarela $(O C B)$ terhadap pekerjaan, dimana guru tidak memandang sekolah sebagai tempat bekerja saja melainkan wadah dirinya dalam berkreativitas dan menunjukkan kompetensi yang dimilikinya. Hal ini akan membuat guru rela melakukan apa saja demi kesuksesan organisasi termasuk dengan membantu rekan guru lainnya dalam menyelesaikan pekerjaan dan senantiasa menjaga hubungan baik dengan rekan guru lainnya.

Berdasarkan uraian di atas secara teoretik maupun empiris, efikasi diri berpengaruh langsung positif terhadap $O C B$.

\section{Pengaruh Kepemimpinan Transformasional terhadap Efikasi Diri}

Dari hasil pengujian hipotesis ketiga dapat disimpulkan bahwa terdapat pengaruh langsung positif kepemimpinan transformasional terhadap efikasi diridengan nilai koefisien korelasi sebesar 0,398 dan nilai koefisien jalur sebesar 0,398.Ini memberikan makna kepemimpinan transformasional berpengaruh langsung terhadap efikasi diri.

Hasil penelitian ini senada dengan pendapat beberapa ahli di antaranya adalah Jyoti Aggarwal dan Venkat R. Krishnan dengan penelitian yang berjudul "Impact of Transformational Leadership on Follower's Self Efficacy". Hasil penelitian menunjukkan adanya pengaruh positif dari kepemimpinan transformasional terhadap efikasi diri. 
Efikasi diri seringkali diartikan sebagai keyakinan atau kepercayaan diri. Jason A. Colquitt, Jeffery A. Lepine, dan Michael J. Wesson (2009:170) mendefinisikan, "self-efficacy defined as the belief that a person has the capabilities needed to execute the behaviors required for task success". Diartikan secara bebas, efikasi diriguru merupakan kepercayaan diri guru bahwa ia memiliki kemampuan yang dibutuhkan untuk menjalankan perilaku yang diperlukan untuk menyukseskan tugasnya.

Saat ini, profesi guru bukanlah profesi yang hanya bertugas untuk mengajar di depan kelas saja. Guru diharapkan untuk menjadi pendidik bagi peserta didik di sekolah. Sebagai seorang pendidik maka pekerjaan guru menjadi lebih kompleks, dimana guru diminta untuk membuat perencanaan pembelajaran, menyiapkan proses belajar yang menyenangkan peserta didik hingga melakukan penilaian peserta didik dalam belajar.

Hal ini tentu membuat beban pekerjaan guru semakin meningkat. Untuk itulah guru diharapkan memiliki efikasi diri yang tinggi sehingga mampu menghadapi semua beban pekerjaan yang ada di sekolah. Efikasi diri guru akan melahirkan motivasi yang tinggi dalam melakukan pekerjaan di sekolah. Namun terkadang berbagai hal dapat membuat guru memiliki efikasi diri yang lemah. Untuk itulah peran kepala sekolah tentu dibutuhkan untuk memotivasi guru sehingga dapat meningkatkan efikasi diri guru.

Salah satu hal yang dapat dilakukan kepala sekolah dalam meningkatkan perannya untuk memotivasi guru adalah dengan menerapkan gaya kepemimpinan transformasional. Gibson et. al., (2006:355) berpendapat bahwa kepemimpinan transformasional adalah, "ability to inspire and motivate followers to achive result greater than originally planned and for internal rewards". Diartikan secara bebas, kepala sekolah yang menerapkan gaya kepemimpinan transformasional adalah pemimpin yang menginspirasi para pengikutnya untuk mengesampingkan kepentingan pribadi mereka demi kebaikan organisasi.

Kepala sekolah dengan gaya kepemimpinan transformasional merupakan teladan bagi guru di sekolah. Kepala sekolah mampu memotivasi guru dengan menjadi inspirasi guru dalam melakukan pekerjaan di sekolah. Kepala sekolah senantiasa menstimulus para guru untuk bekerja lebih keras demi kemajuan organisasi sekolah. Kepala sekolah yang menerapkan kepemimpinan transformasional menaruh perhatian dalam memberikan motivasi terhadap usaha guru agar melakukan pekerjaan dengan lebih sukses.

Berdasarkan uraian di atas secara teoretik maupun empiris, kepemimpinan transformasional berpengaruh langsung positif terhadap efikasi diri.

\section{PENUTUP}

Kesimpulan: Berdasarkan hasil penelitian dan pembahasan yang dikemukakan sebelumnya, dapat dikemukakan kesimpulan sebagai berikut: (1) kepemimpinan transformasional berpengaruh langsung positif terhadap OCB. Artinya, Artinya, 
ketepatankepemimpinan transformasional mengakibatkan peningkatan $O C B$ guru SMK Negeri di Kabupaten Bekasi, (2) efikasi diri berpengaruh langsung positif terhadap OCB.Artinya peningkatan efikasi diri mengakibatkan peningkatan $O C B$ guru SMK Negeri di Kabupaten Bekasi, (3) kepemimpinan transformasional berpengaruh langsung positif terhadap efikasi diri.Artinya, ketepatankepemimpinan transformasional mengakibatkan peningkatan efikasi diri guru SMK Negeri di Kabupaten Bekasi.

Saran: Berdasarkan implikasi penelitian yang dikemukakan di atas dapat diajukan saran-saran praktis yang dapat mendorong peningkatan komitmen guru di sekolah yaitu sebagai berikut: Pertama, saran untuk kepala sekolah. Kepala sekolah sebagai pemimpin di sekolah diharapkan dapat menerapkan gaya kepemimpinan transformasional secara tepat. Pemimpin dengan gaya transformasional akan mampu melakukan perubahan secara nyata dengan cara menggerakkan dan mempercayai bawahan agar bekerja dengan optimal. Selain itu, pemimpin dengan gaya kepemimpinan transformasional juga mampu untuk menangani dan menyelesaikan masalah yang terjadi di sekolah dengan cepat dan tepat. Sehingga visi, misi dan tujuan sekolah dapat terealisasikan. Kedua, saran untuk guru agar meningkatkan efikasi dirinya dengan cara percaya diri dalam menyelesaikan tugas di sekolah tepat waktu, percaya diri dalam menghadapi permasalahan di sekolah baik permasalahan dengan kepala sekolah, rekan kerja maupun peserta didik dan percaya diri dalam mengendalikan keadaan selama di sekolah. Ketiga, saran untuk penelitian selanjutnya.Belum semua masalah $O C B$ guru dapat terjawab melalui penelitian ini.Masih banyak faktor yang berpotensi mempengaruhi OCB guru yang harus dijelaskan melalui penelitian selanjutnya misalnya kepribadian, komitmen organisasi, dan lain-lain.

\section{DAFTAR RUJUKAN}

Chamariyah, Achmad Sudiro, Noermijati dan Rofiaty. The Effect of Transformational Leadership to Organizational Citizenship Behavior (OCB) and Employees Performance (Study Case to PT PLN Persero Pamekasan Area). International Journal of Business and Behavioral Sciences Vol. 5 No.4, April 2015

Colquitt, Jason A, Jeffery LePine, Michael J. Wesson. Organizational Behavior: Improving Performance and Commitment in the Workplace. New York: McGrawHill, 2009

George Jennifer M., Gareth R. Jones. Understanding and Managing Organizational Behavior.New York: McGraw-Hill, 2012

Gibson, James L. James H. Donelly, Jr., John M. Ivancevich, Robert Konopaske. Organizations: Behavior, Structure, Process.New York: McGraw-Hill, 2006 
Hawkins,Peter. Leadership Team Coaching: Developing CollectiveTransformational Leadership. London: Kogan Page, 2011

Ivancevich, John M., Robert Konopaske. Human Resource Management.North America: Mc.Graw Hill, 2013

Kinicki, Angelo, Mel Fugate. Organizational Behavior: Key Concept, Skill and Best Practices. New York: McGraw-Hill, 2012

Kreitner, Robert, Angelo Kinicki. Organizational Behavior Ninth Edition. New York: McGraw-Hill/Irwin, 2010

McShane, Steven L., Mary Ann Von Glinow. Organizational Behavior. New York: McGraw-Hill, 2010

Morse,Ricardo R., Terry F. Buss, Morgan C. Kinghorn. Transforming Public for the 21st Century.London: M.E. Sharpe, 2007

Robbins, Stephen P., Timothy A. Judge. Organizational Behavior. London: Pearson, 2011

Robbins, Stephen P., Mary Coulter. Management Eleventh Edition. New Jersey: Prentice Hall, 2012

Santrock,John W. Educational Psychology. New York: McGraw-Hill, 2008

Schermerhorn Jr.,John R. Exploring Management Third Edition.Hoboken: John Wiley \& Sons, 2012

Sheikh, Iram Naveed.The Impact Of Perfectionism and Self-Efficacy on Organizational Citizenship Behavior $(O C B)$, International Journal of Current Research Vol. 7 Issue. 02, Februari 2015

Slocum, John W., Don Hellriegel. Principles Organizational Behavior.USA: Cengage Learning, 2009 